\title{
Simultaneous Measurements of Atmospheric HONO and NO2 via Absorption Spectroscopy using Tunable Mid-Infrared Continuous-wave Quantum Cascade Lasers
}

\section{Citation}

Lee, Ben H., Ezra C. Wood, Mark S. Zahniser, J. Barry McManus, David D. Nelson, Scott C. Herndon, Gregory W. Santoni, Steven C. Wofsy, and J. William Munger. 2011. Simultaneous measurements of atmospheric HONO and \((NO_2) ) via absorption spectroscopy using tunable mid-infrared continuous-wave quantum cascade lasers. Applied Physics B: Lasers and Optics 102(2): 471-423.

\section{Published Version}

doi:10.1007/s00340-010-4266-5

\section{Permanent link}

http://nrs.harvard.edu/urn-3:HUL.InstRepos:10085277

\section{Terms of Use}

This article was downloaded from Harvard University's DASH repository, and is made available under the terms and conditions applicable to Open Access Policy Articles, as set forth at http:// nrs.harvard.edu/urn-3:HUL.InstRepos:dash.current.terms-of-use\#OAP

\section{Share Your Story}

The Harvard community has made this article openly available.

Please share how this access benefits you. Submit a story.

\section{Accessibility}




\title{
Simultaneous measurements of atmospheric $\mathrm{HONO}$ and $\mathrm{NO}_{2}$ via absorption spectroscopy using tunable mid-infrared continuous-wave quantum cascade lasers
}

\author{
Ben H. Lee ${ }^{1}$, Ezra C. Wood², Mark S. Zahniser², J. Barry McManus², David D. Nelson², Scott C. Herndon², Gregory \\ W. Santoni ${ }^{1}$, Steven C. Wofsy ${ }^{1}$ and J. William Munger ${ }^{1}$ \\ ${ }^{1}$ Harvard University, School of Engineering and Applied Sciences, Cambridge, Ma, U.S.A. \\ ${ }^{2}$ Aerodyne Research, Inc. Center for Atmospheric and Environmental Chemistry, Billerica, Ma, U.S.A.
}

\begin{abstract}
Nitrous acid (HONO) is important as a significant source of hydroxyl radical $(\mathrm{OH})$ in the troposphere and as a potent indoor air pollutant. It is thought to be generated in both environments via heterogeneous reactions involving nitrogen dioxide $\left(\mathrm{NO}_{2}\right)$. In order to enable fast-response HONO detection suitable for eddy-covariance flux measurements and to provide a direct method that avoids interferences associated with derivatization, we have developed a 2-channel tunable infrared laser differential absorption spectrometer (TILDAS) capable of simultaneous high-frequency measurements of $\mathrm{HONO}$ and $\mathrm{NO}_{2}$. Beams from two mid-infrared continuous-wave mode quantum cascade lasers (cw-QCLs) traverse separate $210 \mathrm{~m}$ paths through a multi-pass astigmatic sampling cell at reduced pressure for the direct detection of HONO $\left(1660 \mathrm{~cm}^{-1}\right)$ and $\mathrm{NO}_{2}\left(1604 \mathrm{~cm}^{-1}\right)$. The resulting one-second detection limits $(\mathrm{S} / \mathrm{N}=3)$ are 300 and $30 \mathrm{ppt}(\mathrm{pmol} / \mathrm{mol})$ for $\mathrm{HONO}$ and $\mathrm{NO}_{2}$, respectively. Our HONO quantification is based on revised line-strengths and peak-positions for cisHONO in the 6-micron spectral region that were derived from laboratory measurements. An essential component of ambient HONO measurements is the inlet system and we demonstrate that heated surfaces and reduced pressure minimize sampling artifacts.
\end{abstract}

\section{Introduction}

Atmospheric nitrous acid (HONO) photo-dissociates with a lifetime between 10 and 20 minutes to yield nitric oxide (NO) and hydroxyl radical $(\mathrm{OH})$, the main oxidant in the atmosphere. Nighttime HONO formation and photolysis at sunrise can contribute significantly to early morning photochemistry. Observations of mid-day HONO concentrations above levels expected from photo-stationary balance between HONO, NO and $\mathrm{OH}$ suggest a yet unidentified light-dependent production mechanism. These measurements have used various instruments in a wide range of environments [1-3]. Thus, HONO may make a larger contribution to the $\mathrm{HO}_{\mathrm{x}}\left(=\mathrm{OH}+\mathrm{HO}_{2}\right)$ cycle in the lower troposphere than has been accounted for by its nighttime formation. In addition, HONO chemistry may contribute to reactivating deposited nitrogen, which was presumed to be permanently removed from photochemical cycle. HONO is also an indoor air pollutant - both emitted directly from combustion processes and formed on various surfaces - and can react with amines to form carcinogenic compounds $[4,5]$. $\mathrm{NO}_{2}$ is proposed as a precursor to HONO formation via heterogeneous reactions. In order to examine the exchange of HONO between the biosphere and atmosphere and the role of $\mathrm{NO}_{2}$ in this exchange, we have developed a dual-laser spectrometer to simultaneously measure both gases. 
Several factors make accurate HONO measurements difficult. It is unstable so certified reference gases for HONO do not exist. Its reactivity and solubility also make it prone to sampling losses and artifacts. Consequently, inter-comparisons between different techniques often exhibit significant discrepancies $[2,6]$. Further progress on understanding HONO sources and sinks requires a sensitive and unambiguous measurement method.

There are many methods to detect HONO, but they do not fully satisfy the need for sensitivity, selectivity and fast time response. Analytical techniques based on derivatization partition gaseous HONO into a liquid and subsequently measure the nitrite ion or its derivative by ion or liquid chromatography, long-path photometry or chemiluminescence [4, 7-9]. Although these methods can be very sensitive, the need to scrub HONO into solution may introduce sensitivity to any other gas-phase species that react with the solution [6]. Such interferences can be corrected if the chemically active species is quantifiable [10]. Furthermore, the need for long extraction integration times (a few minutes) precludes the application of these methods to eddy-covariance flux measurements.

Absorption spectroscopy directly measures atmospheric trace gases without the need for chemical extraction, with calibrations that are based on constant absorption cross-sections (line-strengths) and specificity that can be confirmed by spectral identification. However, absorption spectroscopic analytical methods tend to be expensive, and for many trace gases the fundamental sensitivity is relatively low, requiring either long absorption paths or increased signal averaging time. Both open-path (differential optical absorption spectroscopy, DOAS) $[1,11,12]$ and closed-path (tunable diode laser absorption spectroscopy, TDLAS) $[13,14]$ systems have been utilized to measure HONO. Based on a prior implementation of nitric acid $\left(\mathrm{HNO}_{3}\right)$ and $\mathrm{NO}_{2}$ TDLAS [15-17], we have developed a dual-channel tunable infrared laser differential absorption spectrometer (TILDAS) using continuous-wave quantum-cascade lasers instead of diode lasers to measure $\mathrm{HONO}$ and $\mathrm{NO}_{2}$. The advantages of using $\mathrm{cw}$-QC lasers in TILDAS over diode lasers in TDLAS are greater mode stability, higher laser power output and the ability to operate both lasers and detectors near room temperature without the need for cryogenic cooling, which facilitates long-term field measurements. The spectrometer is coupled with sample handling and calibration schemes intended to minimize inlet artifacts and provide quality-assurance that the system is working properly. Section 2 describes the spectrometer design and quantifies performance. Section 3 presents results from the investigation of HONO line-strengths and peak-positions. Section 4 describes the sampling scheme and presents preliminary results from field measurements demonstrating the absence of positive and negative artifacts.

\section{Instrument}

The main components of the optical table (Figure 1) include two light sources, a reference cell, multi-pass sampling cell and two detectors. For the light source, the spectrometer uses two thermo-electrically cooled QC lasers (Alpes Lasers) operated in continuous-wave mode that output light in the 6-micron spectral region. The laser light is scanned across a frequency spectrum in time by controlling its temperature, which is coarsely tuned with a Peltier element and finely tuned on a milli-Kelvin scale by providing the lasers with a programmable current ramp using a high compliance current source (ILX Lightwave). The 
resulting laser frequency scan covers approximately $0.2 \mathrm{~cm}^{-1}$ with a resolution of about $0.001 \mathrm{~cm}^{-1}$ per channel. The instrumental line-widths for both lasers are less than $0.001 \mathrm{~cm}^{-1}$ (half-width at half-maximum), which is smaller than Doppler broadened widths. The tuning rates of each laser are determined with a germanium etalon.

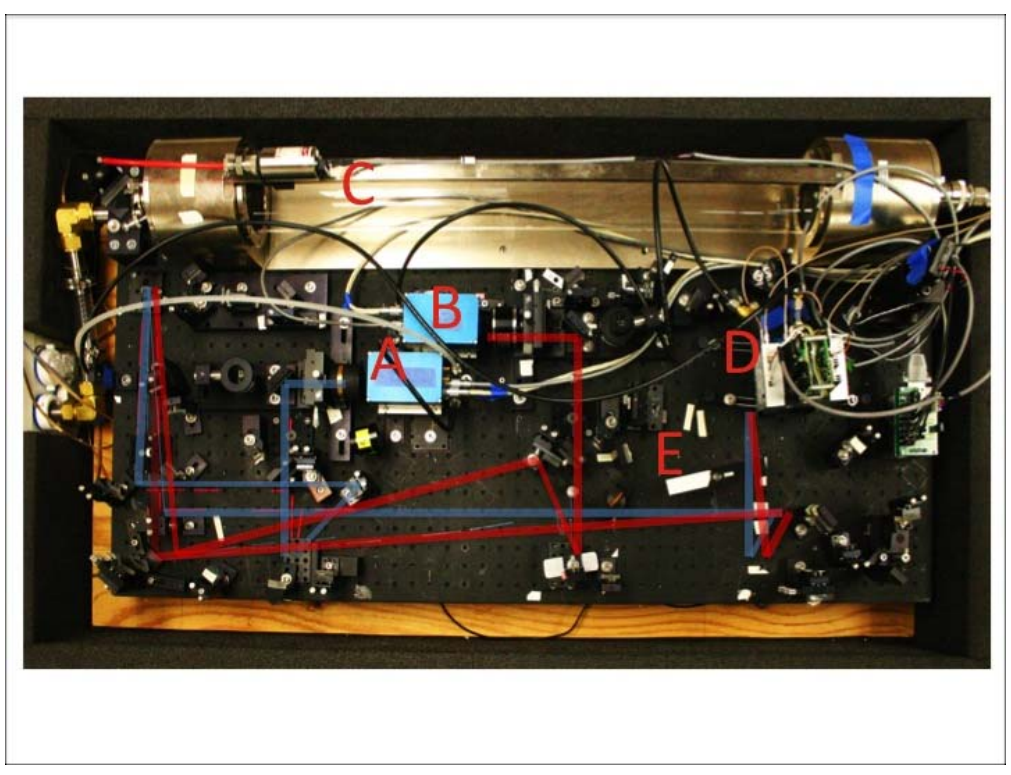

Figure 1. Optical table of the dual $\mathrm{cw}-\mathrm{QC}$ laser spectrometer. $\mathrm{A}=\mathrm{QC}$ laser $\left(1660 \mathrm{~cm}^{-1}, \mathrm{HONO}\right) ; \mathrm{B}=\mathrm{QC}$ laser $\left(1604 \mathrm{~cm}^{-1}, \mathrm{NO}_{2}\right) ; \mathrm{C}=$ astigmatic multi-pass sampling cell; $\mathrm{D}=$ thermo-electrically cooled detector; $\mathrm{E}=$ reference cell filled with $\mathrm{NO}_{2}$ and HONO. The blue and red traces represent paths traveled by the HONO $\left(1660 \mathrm{~cm}^{-1}\right)$ and $\mathrm{NO}_{2}\left(1604 \mathrm{~cm}^{-1}\right)$ laser light, respectively. The traces for the reference cell and normalization are not shown. The optical table has a footprint of $2 \mathrm{ft} \times 4 \mathrm{ft}(0.6 \mathrm{~m} \times 1.2 \mathrm{~m})$.

The two lasers are spatially and temporally multiplexed so that even though light from each laser traverses distinct paths inside and outside the sampling cell, both beams are collected by a single detector at alternate times on the order of $1 \mathrm{~ms}$ for each laser. The spectra for $\mathrm{NO}_{2}$ (1604.5 to $1604.7 \mathrm{~cm}^{-1}$ ) and HONO (1659.5 to $1659.7 \mathrm{~cm}^{-1}$ ) are repeatedly scanned one after the other at a total rate of about $3 \mathrm{kHz}$ and are subsequently averaged in real-time to improve the signal to noise ratio. Approximately $10 \%$ of the duty cycle is dedicated to measuring the detector zero light level when both lasers are off. The spectral fitting software (TDLWintel, also responsible for the laser control) determines the absorbance by performing a non-linear fit according to a set of Voigt line shape functions to the recorded spectra and a low-order polynomial fit to the spectral baseline. Mixing ratios are calculated by accounting for the sample pressure and temperature along with spectral broadening and IR linestrengths archived in the HITRAN database for $\mathrm{NO}_{2}$ [18] and determined experimentally here for HONO (discussed below). Figure 2 shows transmission spectra of $\mathrm{HONO}$ and $\mathrm{NO}_{2}$ observed during calibration gas additions. 


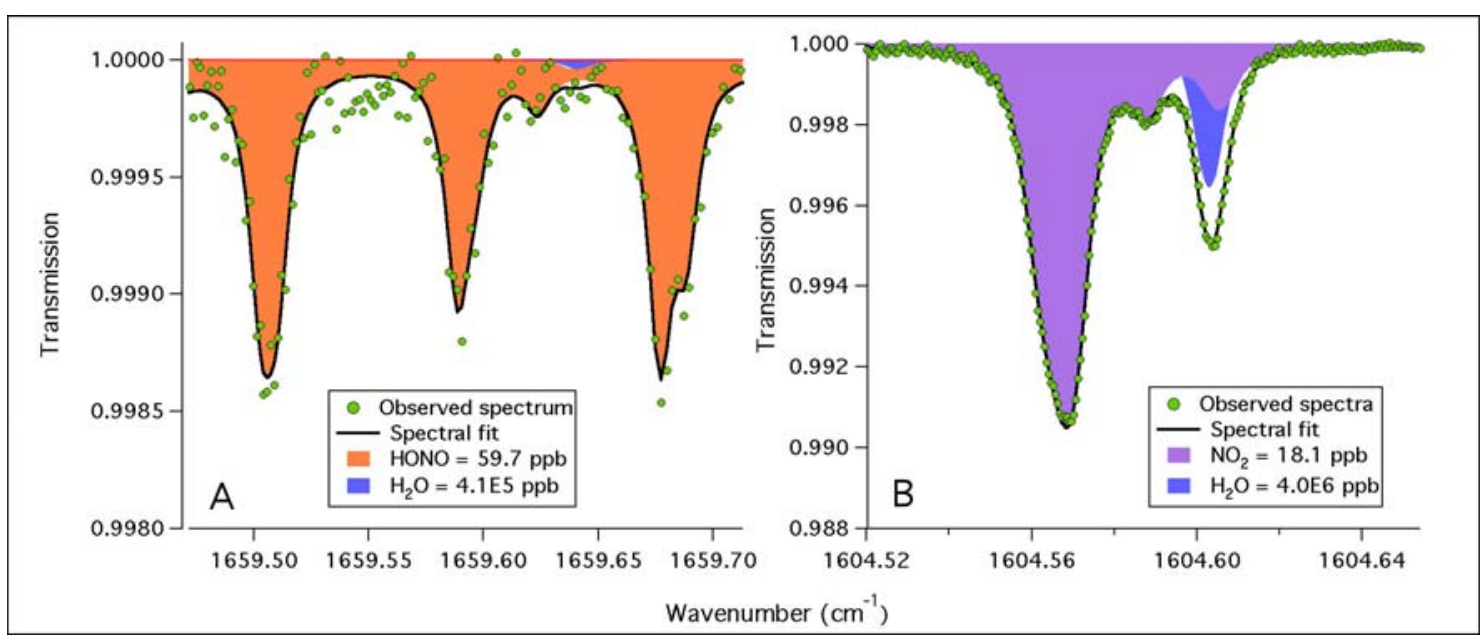

Figure 2. Transmission spectra, averaged over 30-seconds, of $(\mathrm{A}) \mathrm{HONO}$ and $(\mathrm{B}) \mathrm{NO}_{2}$ at 40 torr. The colored areas represent the fits to the observed spectra (green dots) according to the known peak-position, linestrength and recorded pressure and temperature.

Ambient air is sampled through an inlet and transported in tubing (discussed below) to the sampling cell, which is maintained at a constant reduced pressure to minimize spectral overlap with other infrared-light absorbing species (especially water), while maintaining sufficient absorption depths for high sensitivity. Light from each laser enters the multi-pass cell and reflects between two astigmatic mirrors with multilayer dielectric coatings (reflectivity $\sim 0.998$, LohnStar Optics, Inc.). The mirrors are spaced $0.88 \mathrm{~m}$ apart and obtain 238 passes, resulting in a total path-length of $210 \mathrm{~m}$. The light exits the cell through the entrance coupling-hole and is directed onto a thermo-electrically cooled detector (Vigo). It should be noted that a liquid-nitrogen cooled HgCdTe detector - which due to its larger active detector area is less susceptible to aiming changes - could be used to improve overall stability. However, the costs and measurement interruptions associated with liquid nitrogen fills for a comparable level of sensitivity with the HgCdTe detectors, make the thermoelectrically cooled detectors a preferred option.

The optical table also includes secondary and tertiary light paths, both external to the sampling cell - derived from the reflections off the front and back surfaces of a transmission beam splitter. One path is directed through a $7 \mathrm{~cm}$ path-length reference cell filled with gaseous $\mathrm{HONO}$ and $\mathrm{NO}_{2}$. The spectra of this transmitted light is continuously measured by a second detector and is used to "lock" the lasers to the desired absorption features of HONO and $\mathrm{NO}_{2}$, which is necessary when ambient levels of the species of interest are too low to observe significant absorbance in real-time and also preferred for the routine additions of zero-air, or ambient air scrubbed of these gases. The third beam and detector could be used to normalize out power variability associated with the light source, if desired, but has not been implemented. Details regarding the laser control, optical trace and alignment, data acquisition system, spectral fitting software, detectors and sampling cell have been discussed at length previously [17, 19-22]. 
Absorbance precisions less than $3 \times 10^{-6} \mathrm{~Hz}^{-1 / 2}\left(1.4 \times 10^{-10} \mathrm{~cm}^{-1} \mathrm{~Hz}^{-1 / 2}\right)$ and $5 \times 10^{-6} \mathrm{~Hz}^{-1 / 2}$ $\left(1.9 \times 10^{-10} \mathrm{~cm}^{-1} \mathrm{~Hz}^{-1 / 2}\right)$ are achieved for $\mathrm{HONO}$ and $\mathrm{NO}_{2}$, respectively. The $\mathrm{NO}_{2}$ channel is slightly noisier due to the inherent variability of this particular QC device. We achieve the same absorbance precision as that of HONO by utilizing normalization [22]. Normalization with intermittent peak-position locking could be implemented in this dual detector configuration, however, it does not improve HONO sensitivity. Furthermore, at the low HONO mixing ratios expected in rural environments, intermittent line-locking is not adequate to maintain the laser tuning. We sacrifice some $\mathrm{NO}_{2}$ sensitivity, which is not needed for typical ambient $\mathrm{NO}_{2}$ levels, to ensure accurate $\mathrm{HONO}$ spectroscopy. For measurements at cell pressure of 40 torr, the one-second $1-\sigma$ precisions for $\mathrm{HONO}$ and $\mathrm{NO}_{2}$ are 100 and 10 ppt ( 6 ppt if absorbance precision observed for $\mathrm{HONO}$ is achieved for $\mathrm{NO}_{2}$ ), respectively. Long-term stability is limited by optical fringes that change with temperature, causing drifts in the spectral baseline. These effects may be minimized by frequent background spectrum subtractions obtained by flushing the cell with $\mathrm{HONO}$ and $\mathrm{NO}_{2}$ scrubbed air, or zero-air, which is generated by passing ambient air over a heated palladium catalyst. This source of zero-air does not significantly alter the water-vapor mixing ratio, which is critical because there are weakly absorbing $\mathrm{H}_{2} \mathrm{O}$ features in both the $\mathrm{HONO}$ and $\mathrm{NO}_{2}$ scans (Figure 2). Time averaging improves the precision of $\mathrm{HONO}$ and $\mathrm{NO}_{2}$ measurements by a factor of 10 or better over an integration time of 30 minutes, which is a typical interval to compute eddy covariance over a forest canopy, with background spectra subtractions conducted once every 5 minutes (Figure 3).

Figure 3. The top two panels show $\mathrm{HONO}$ (blue) and $\mathrm{NO}_{2}$ (red) mixing ratios in ppt (pmol/mol) measured in zero-air at 40 torr. The Allan variance plot on the bottom panel shows the decrease in instrument variance with time averaging for both species. Deviation from pure white or random noise occurs due to slow-moving temperature-driven optical fringes, but is addressed with frequent spectral background subtractions, here conducted every fifth minute for 30 seconds $(20$ seconds to obtain an average background spectrum and 10 seconds of flush time). The y-intercepts on the Allan variance plot representing the 1-second $1 \sigma$ measurement noise for $\mathrm{HONO}$ and $\mathrm{NO}_{2}$ are $9.4 \times 10^{3}$ and $8.8 \times 10^{1} \mathrm{ppt}^{2} \mathrm{~Hz}^{-1}$, or 97 and $9.4 \mathrm{ppt} \mathrm{Hz}-1 / 2$, respectively. 
An optimal spectral region is selected based upon the maximum absorption cross-section and minimum absorbance by other gases that may be present in the sample. We selected the 6-micron region (Figure 2) where lasers, detectors and mirrors were all available allowing simultaneous measurements of $\mathrm{HONO}$ and $\mathrm{NO}_{2}$. There are, however, alternative spectral regions where HONO absorbs mid-infrared light much more strongly, which may improve sensitivity. In particular, HONO absorption lines at 1708.998, 1713.511, 1247.165 and $1273.598 \mathrm{~cm}^{-1}$ may increase precision by a factor of three to five, however, the 8.0 micron region would be costly for $\mathrm{NO}_{2}$ measurement sensitivity and at this time no appropriate lasers are available in the 5.8 micron region.

\section{3. $\quad$ Line-strengths}

The accuracy of the mixing ratios obtained using absorption spectroscopy largely depends on the accuracy of the absorption cross-section or line-strength. For long-lived gases and other well-studied species such as $\mathrm{NO}_{2}$, the absorption parameters are well characterized and available in publications and in databases such as HITRAN [18]. For HONO, however, there are fewer published studies and greater uncertainty in absolute values, which required us to re-evaluate the HONO spectra.

We determined the amount of infrared (1659.1 to $1660.2 \mathrm{~cm}^{-1}$ ) light absorbed by the cis conformer of HONO while sampling a known amount of total (cis + trans) HONO at the given constant temperature of $303 \mathrm{~K}$, hence at a constant cis to trans ratio. This effective linestrength of cis-HONO was obtained by introducing high levels of gaseous HONO (between 300 and $800 \mathrm{ppb}$ ) - generated by passing $\mathrm{HCl}$ vapor over powdered $\mathrm{NaNO}_{2}$ [23] - into the sampling cell at low pressures ( $<9$ torr) to minimize absorption line overlap while maintaining high signal to noise. In parallel, we quantitatively converted the same HONO source to NO using a heated molybdenum catalyst and quantified NO with a pulsed-mode QC laser (1906.73 $\mathrm{cm}^{-1}$, Hamamatsu Photonics) spectrometer calibrated against a traceable NO standard to determine the absolute HONO concentration. Because NO is relatively inert, it is less susceptible to line-losses and can be accurately calibrated using traceable gas mixtures.

Deviation of the sample from the temperature at which our effective line-strengths were determined will result in a change in the cis to trans ratio. The effective line-strengths can be corrected knowing the cis-trans energy barrier, for which there is a large discrepancy amongst reported values [24-28]. In practice, a constant sample temperature is well maintained by heating the inlet, tubing, the optical table and its protective cover. Furthermore, routine calibration gas additions are conducted in the field to ensure the accuracy of the measurements, as discussed in the next section. Lastly, because the time required for isomerization to occur is much shorter $\left(\sim 10^{-12}\right.$ seconds) than that needed for ambient air to travel through the inlet and subsequent tubing to the sampling cell $(\sim 1$ second), we expect the HONO conformers to be in thermal equilibrium and independent of changing ambient conditions. 
Line positions and effective line-strengths used in the spectral fits in Figure 2 are listed in Table 1. Additional details regarding this experiment, along with comparison of the relative absorption strengths between cis and trans conformers, determination of the pressurebroadening coefficient, comparison to values in the ATMOS database and to a highresolution FTIR spectrum are part of an ongoing analysis that is not yet complete.

Table 1. Peak-position and effective line-strength of cis-HONO between 1659.5 and $1659.7 \mathrm{~cm}^{-1}$ measured at $303 \mathrm{~K}$.

\begin{tabular}{c|c} 
Peak position $\left(\mathrm{cm}^{-1}\right)$ & $\begin{array}{c}\text { Effective line-strength }\left(\mathrm{cm}^{2} \text { molecule-1 }\right. \\
\left.\mathrm{cm}^{-1}\right) \times 10^{-21}\end{array}$ \\
\hline 1659.5031 & 9.571 \\
\hline 1659.5099 & 8.810 \\
\hline 1659.5887 & 10.15 \\
\hline 1659.5968 & 3.283 \\
\hline 1659.6238 & 1.863 \\
\hline 1659.6770 & 12.92 \\
\hline 1659.6886 & 7.419
\end{tabular}

\section{Sampling technique}

Figure 4 shows a schematic of the inlet manifold we use for minimizing contact between sampled ambient air and moist surfaces, for removing coarse particles by inertial separation and for routine additions of reference gases and zero-air. HONO (Henry's Law constant, $\mathrm{K}_{\mathrm{H}}=$ $\left.50 \mathrm{M} \mathrm{atm}^{-1}\right)$ - though not nearly as soluble as $\mathrm{HNO}_{3}\left(\mathrm{~K}_{\mathrm{H}}=2.1 \times 10^{5} \mathrm{M} \mathrm{atm}^{-1}\right)$ - is still photochemically active, relatively soluble compared to $\mathrm{NO}\left(1.4 \times 10^{-3} \mathrm{M} \mathrm{atm}^{-1}\right)$ and $\mathrm{NO}_{2}\left(1.2 \times 10^{-2} \mathrm{M}\right.$ $\mathrm{atm}^{-1}$ ), and mostly dissociated above $\mathrm{pH} 3.3$ [29-32]. In addition to the high probability of HONO equilibrating with accumulated particles and moist surfaces, there is strong evidence for heterogeneous reactions converting precursors to HONO [33]. Consequently, both positive and negative HONO artifacts are a concern, leading us to minimize opportunities for the sample to contact humid surfaces and aerosol that would accumulate on a particle filter.

Surface-adsorbed water is minimized by 1) using a siloxyl-coated quartz inlet to make its surface hydrophobic, 2) heating the inlet, the downstream tubing and sampling cell and 3) reducing the pressure by drawing the sample through a critical orifice built into the inlet (Figure 4). The divergent flows after the orifice - with exhaust vented in line with the incoming flow and the sample air forced to make a $180^{\circ}$ turn - cause particles with diameters $4 \mu \mathrm{m}$ or larger to be separated out of the sample flow by inertia [34,35]. The inlet and subsequent tubing are shielded from light to avoid photolytic losses and photoenhanced reactions involving surface adsorbed nitrate ions leading to HONO production [33]. A similarly designed inlet was used successfully to measure formaldehyde, formic acid and ammonia, which are also highly surface active [36, 37].

Frequent in-field artifact testing is an integral part of the instrument system. The manifold is equipped with ports at the entrance of the inlet to allow for routine additions of standards 
and zero-air (Figure 4). An outlet adjacent to the flow-restricting orifice is used to draw a subsample of the ambient matrix to a heated Mo catalyst to convert all reducible nitrogen oxides to NO, followed by quantification of the $\mathrm{NO}$ by $\mathrm{O}_{3}$-chemilumiscence. HONO generated from the $\mathrm{HCl}+\mathrm{NaNO}_{2}$ source, which typically is $>97 \%$ pure, is dynamically mixed with zero-air, added at the inlet entrance in excess of the total sample flow-rate and sampled by both instruments, thereby providing an independent check on the measurements by tying the observations to traceable NO standards. A similar test is applied for $\mathrm{NO}_{2}$, which is supplied from either compressed gas standards or a permeation tube.

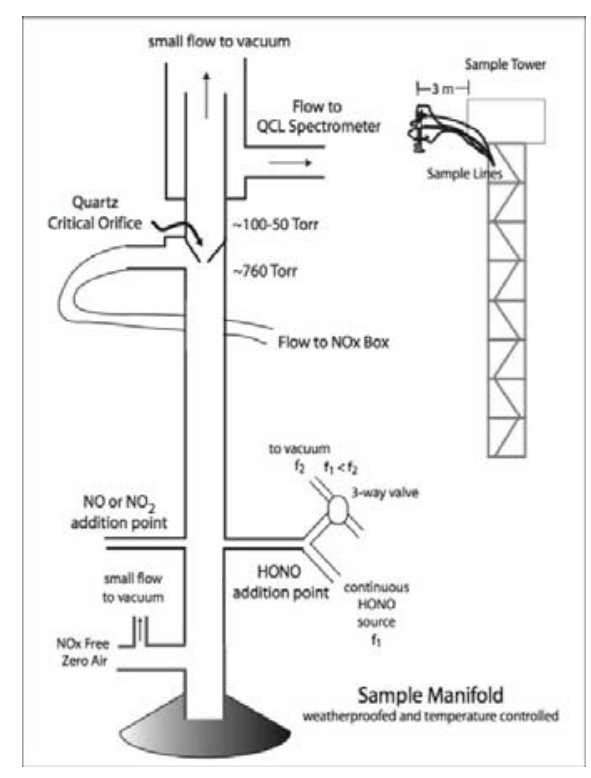

Figure 4. Schematic of the quartz inlet manifold. The inlet and subsequent tubing are shielded from light to prevent photolysis and photo-induced surface reactions.

Standard gas additions can also test for temporary surface adsorption that attenuates atmospheric variations. The rise and fall in absorbance when a standard is switched on or off should be nearly instantaneous, with only some delay associated with the flushing time defined by the pumping speed through the inlet, tubing and sampling cell as well as smearing due to mixing and diffusion. These response times can be determined by fitting the mixing ratio time series during standard gas additions to a single exponential curve. A slower response of HONO compared to that of an inert gas would suggest some uptake of HONO on the surfaces. For the current instrumental configuration, HONO response is compared to that of $\mathrm{NO}_{2}$, which also is generally not attenuated by wall interactions [15-17]. A prototype of this inlet system was deployed at the Study of Houston Atmospheric Radical Precursor (SHARP) campaign in April and May 2009, during which polluted, humid air was sampled through the inlet and $40 \mathrm{ft}$ (12.2 m) of 3/8" O.D. (9.5 mm) PFA Teflon tubing. Figure 5 shows indistinguishable response times between $\mathrm{HONO}$ and $\mathrm{NO}_{2}$ during additions of both gases at SHARP. 
The possibility for positive artifacts from the inlet, tubing or cell surface reactions forming $\mathrm{HONO}$ is checked by introducing $\mathrm{NO}_{2}$ into the inlet in addition to the ambient air matrix. An increase in HONO mixing ratios during these additions would indicate reactions involving $\mathrm{NO}_{2}$ yielding HONO. During the SHARP campaign, we did not observe any artifact HONO when $\mathrm{NO}_{2}$ was added to ambient air (Figure 6). Even at $\mathrm{NO}_{2}$ levels exceeding $100 \mathrm{ppb}$ - well above the range of observed values - there was no change in the HONO mixing ratio, demonstrating freedom from positive artifacts based on $\mathrm{NO}_{2}$.

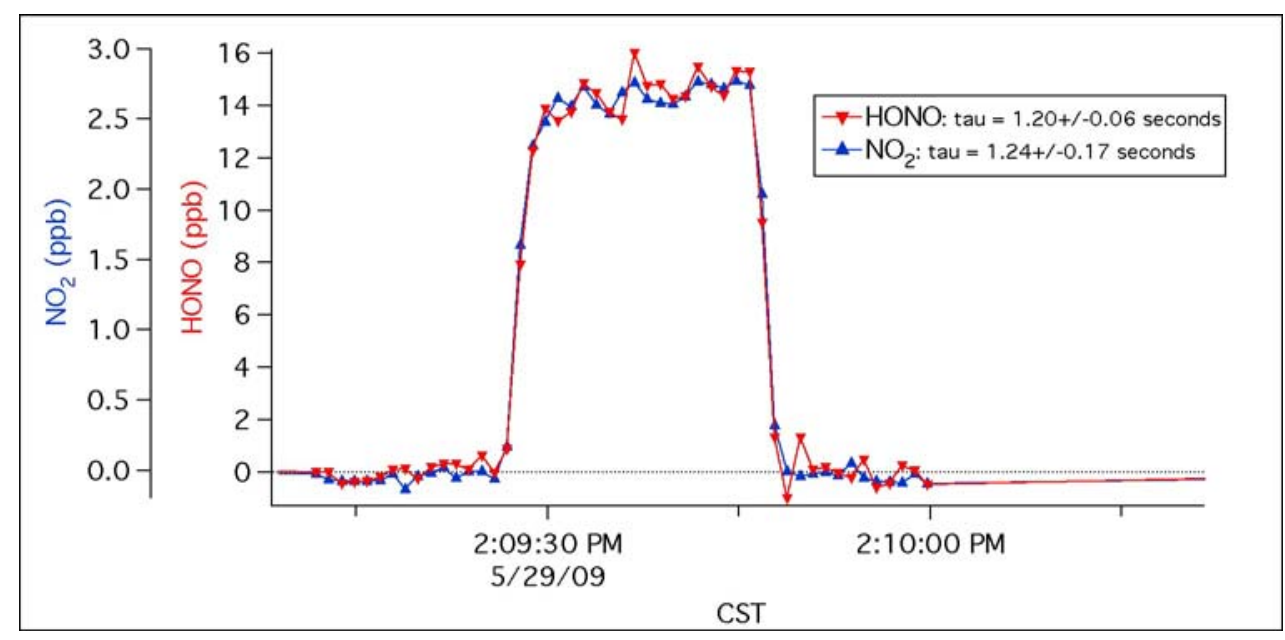

Figure 5. One-second mixing ratios of $\mathrm{HONO}$ and $\mathrm{NO}_{2}$ during calibration gas additions, observed during the Study of Houston Atmospheric Radical Precursor (SHARP) campaign in April and May of 2009. The response times (tau) - determined by the pumping speed and cell volume (5 L) - of $\mathrm{HONO}$ and $\mathrm{NO}_{2}$ are indistinguishable, indicating no preferential loss of HONO through the inlet, tubing and sampling cell.

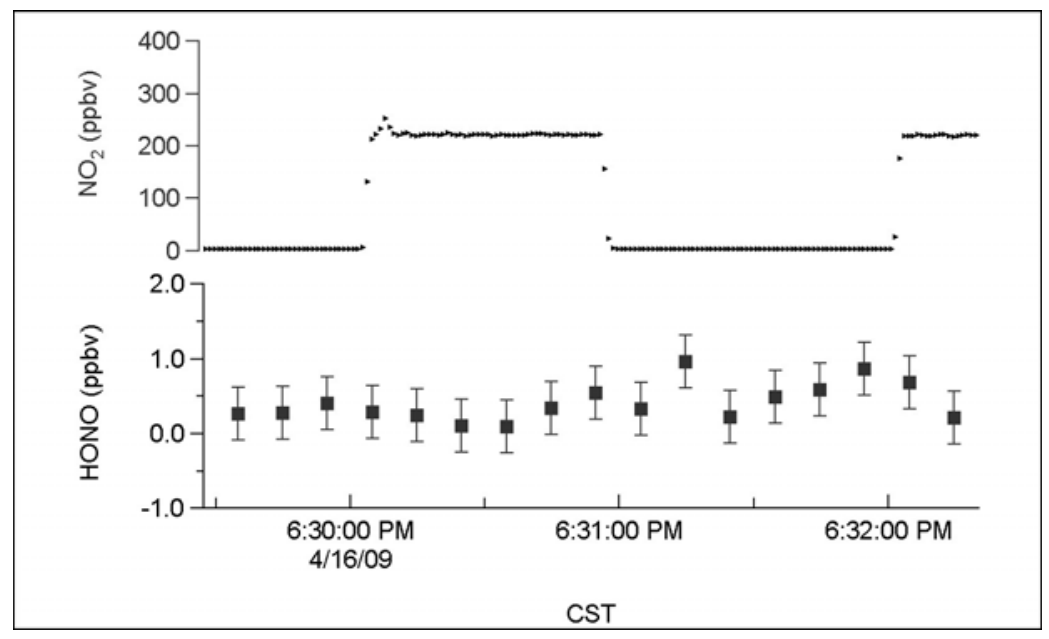


Figure 6. One-second mixing ratios of $\mathrm{NO}_{2}$ (top) and ten-second average mixing ratios of HONO (bottom) during a high-concentration $\mathrm{NO}_{2}$ addition through 40 -feet $(12.2 \mathrm{~m}$ ) of unheated tubing at ambient pressure, conditions under which surface reactions are favored. Note that there is no HONO formed during or immediately following high levels of $\mathrm{NO}_{2}$ under humid conditions (no positive artifact). The error bars represent the standard deviation of 10 -second averaged data.

Figure 7 shows the mixing ratios of $\mathrm{HONO}$ and $\mathrm{NO}_{2}$ measured during the SHARP campaign. The levels of the two species typically co-vary in time as a result of common or co-located emission sources and mixing in the atmosphere. Higher levels are usually observed in the early morning and in the evening when weaker vertical mixing and shallow boundary layer heights promote accumulation of pollutants and photo-chemical losses are reduced compared to mid-day conditions.

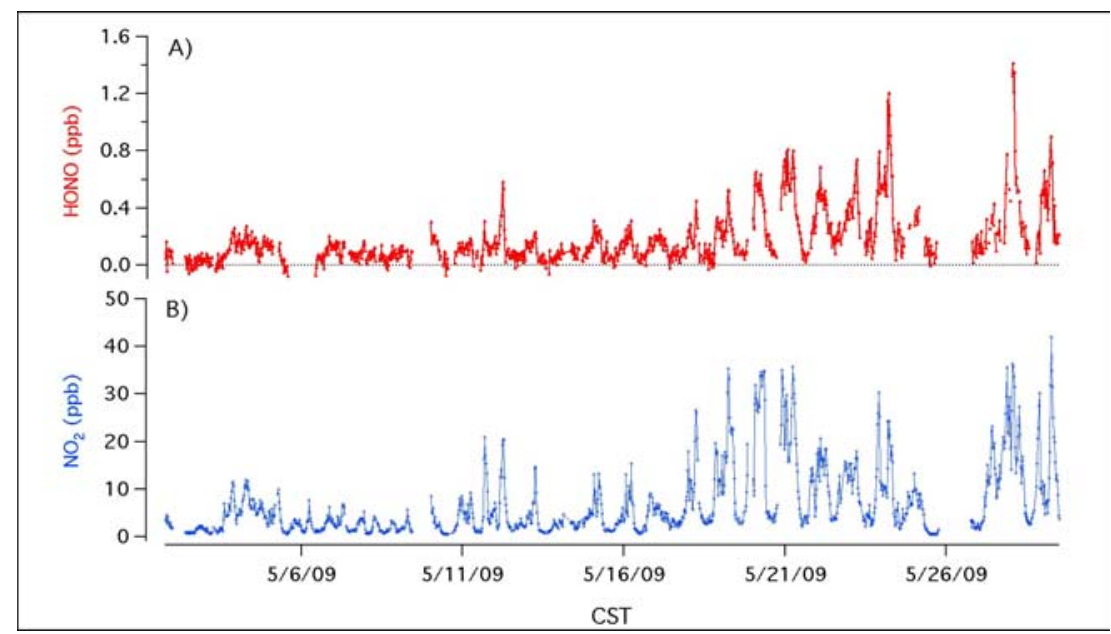

Figure 7. Observed 30-minute averaged mixing ratios in ppb (nmol/mol) of $\mathrm{HONO}(\mathrm{A})$ and $\mathrm{NO}_{2}$ (B) during the entire SHARP campaign. Gaps in the data are due to maintenance operations, inlet attenuation/artifact tests and instrument shutdown from power failures.

\section{Conclusions}

This dual continuous-wave mode quantum cascade laser spectrometer has achieved onesecond detection limits $(\mathrm{S} / \mathrm{N}=3)$ for $\mathrm{HONO}$ and $\mathrm{NO}_{2}$ of 300 and $30 \mathrm{ppt}$, respectively. Spectral averaging with frequent background subtractions allows further reduction in signal noise, improving the $\mathrm{HONO}$ and $\mathrm{NO}_{2}$ detection limits $(\mathrm{S} / \mathrm{N}=3)$ to 35 and $3 \mathrm{ppt}$, respectively, over a 30-minute integration period. The detection limit for $\mathrm{HONO}$ is higher than that for $\mathrm{NO}_{2}-$ despite better absorbance precision on this channel - due to much weaker line-strengths for cis-HONO between 1659 and $1660 \mathrm{~cm}^{-1}$ compared to $\mathrm{NO}_{2}$ at $1604 \mathrm{~cm}^{-1}$. A sample-handling scheme that minimizes adsorbed water on the inlet and subsequent tubing that bring sample into the optical cell is effective at preventing both positive and negative HONO artifacts. The system is designed to allow inlet checks to be a part of routine field operation and provide frequent quality checks on the measurement. 
The instrument described in this study was adapted from a previously deployed instrument with a large optical table and near $1 \mathrm{~m}$ base-length multi-pass cell. With insulation and a protective cover, the instrument is $3 \mathrm{ft} \times 6 \mathrm{ft}(0.9 \mathrm{~m} \times 1.8 \mathrm{~m})$. The performance demonstrated by this implementation points to the possibility of using a re-designed astigmatic multi-pass cell with a base-length of $47.5 \mathrm{~cm}$ and $200 \mathrm{~m}$ of absorption path-length. This cell fits on an optical table measuring $43 \times 65 \mathrm{~cm}$. Its smaller volume of $1 \mathrm{~L}$ allows faster response times and will be more easily portable for field use without any sacrifice in detection limit [38].

The chief advantages of this dual cW-QC TILDAS spectrometer over previous diode laser and pulsed-mode QC laser systems are higher power output and narrower laser line-widths, which provide improved precision and enable thermo-electrically cooled detectors to be used instead of cryogenically cooled detectors that present logistical challenges for longterm, remote operation in the field. This spectrometer has been deployed at a rural forest to measure the diurnal and seasonal trends in the exchange of $\mathrm{HONO}$ and $\mathrm{NO}_{2}$ between the biosphere and atmosphere.

\section{Acknowledgments}

The authors gratefully acknowledge the assistance of Ryan McGovern, Stanley Huang and Daniel Glen of Aerodyne Research, Inc., Josh McLaren and Bruce Daube of Harvard University, and the entire SHARP research team. This work was supported by the National Science Foundation Awards No. AGS - 0813617 and 0814202. Additional funding for the SHARP campaign was provided by the Houston Advanced Research Center Grant No. H113.

\section{References}

1. Alicke, B., et al, OH formation by HONO photolysis during the BERLIOZ experiment. Journal of Geophysical Research-Atmospheres, 2003. 108(D4): p. - .

2. Liao, W., et al, Observations of HONO by laser-induced fluorescence at the South Pole during ANTCI 2003. Geophysical Research Letters, 2006. 33(9): p. -

3. Zhou, X.L., et al., Summertime observations of HONO, HCHO, and O-3 at the summit of Whiteface Mountain, New York. Journal of Geophysical Research-Atmospheres, 2007. 112(D8): p. -.

4. Park, S.S., et al, Investigation of nitrous acid concentration in an indoor environment using an in-situ monitoring system. Atmospheric Environment, 2008. 42(27): p. 6586-6596.

5. Sleiman, M., et al, Formation of carcinogens indoors by surface-mediated reactions of nicotine with nitrous acid, leading to potential thirdhand smoke hazards. Proceedings of the National Academy of Sciences of the United States of America, 2010. 107(15): p. 6576-6581.

6. Kleffmann, J., et al, Intercomparison of the DOAS and LOPAP techniques for the detection of nitrous acid (HONO). Atmospheric Environment, 2006. 40(20): p. 3640-3652.

7. Dibb, J.E., et al, Soluble reactive nitrogen oxides at South Pole during ISCAT 2000. Atmospheric Environment, 2004. 38(32): p. 5399-5409.

8. Heland, J., et al, A new instrument to measure gaseous nitrous acid (HONO) in the atmosphere. Environmental Science \& Technology, 2001. 35(15): p. 3207-3212.

9. Zhou, X.L., et al., A method for the measurement of atmospheric HONO based on DNPH derivatization and HPLC analysis. Environmental Science \& Technology, 1999. 33(20): p. 3672-3679.

10. Kleffmann, J. and P. Wiesen, Technical Note: Quantification of interferences of wet chemical HONO LOPAP measurements under simulated polar conditions. Atmospheric Chemistry and Physics, 2008. 8: p. 6813-6822. 
11. Kurtenbach, R., et al, Investigations of emissions and heterogeneous formation of HONO in a road traffic tunnel. Atmospheric Environment, 2001. 35(20): p. 3385-3394.

12. Platt, U., et al., Observations of Nitrous-Acid in an Urban Atmosphere by Differential Optical-Absorption. Nature, 1980. 285(5763): p. 312-314.

13. Li, Y.Q., J.J. Schwab, and K.L. Demerjian, Fast time response measurements of gaseous nitrous acid using a tunable diode laser absorption spectrometer: HONO emission source from vehicle exhausts. Geophysical Research Letters, 2008. 35(4): p. - .

14. Schiller, C.L., et al, Atmospheric measurements of HONO by tunable diode laser absorption spectroscopy. Journal of Atmospheric Chemistry, 2001. 40(3): p. 275-293.

15. Horii, C.V., et al., Fluxes of nitrogen oxides over a temperate deciduous forest. Journal of Geophysical Research-Atmospheres, 2004. 109(D8): p. -

16. Horii, C.V., et al., Atmospheric reactive nitrogen concentration and flux budgets at a Northeastern US forest site. Agricultural and Forest Meteorology, 2005. 133(1-4): p. 210-225.

17. Horii, C.V., et al., Nitric Acid and Nitrogen Dioxide Flux Measurements: a new Application of Tunable Diode Laser Absorption Spectroscopy. Proceedings of SPIE, 1999. 3758: p. 152-161.

18. Rothman, L.S., et al, The HITRAN 2004 molecular spectroscopic database. Journal of Quantitative Spectroscopy \& Radiative Transfer, 2005. 96(2): p. 139-204.

19. McManus, J.B., Paraxial matrix description of astigmatic and cylindrical mirror resonators with twisted axes for laser spectroscopy. Applied Optics, 2007. 46(4): p. 472-482.

20. McManus, J.B., et al, Comparison of $c w$ and pulsed operation with a TE-cooled quantum cascade infrared laser for detection of nitric oxide at $1900 \mathrm{~cm}(-1)$. Applied Physics B-Lasers and Optics, 2006. 85(2-3): p. 235-241.

21. Nelson, D.D., et al., Sub-part-per-billion detection of nitric oxide in air using a thermoelectrically cooled mid-infrared quantum cascade laser spectrometer. Applied Physics B-Lasers and Optics, 2002. 75(2-3): p. 343-350.

22. Zahniser, M.S., et al, Infrared QC laser applications to field measurements of atmospheric trace gas sources and sinks in environmental research: enhanced capabilities using continuous wave QCLs. Proceedings of SPIE, 2009. 7222, 72220H.

23. Febo, A., et al, Evaluation of a High-Purity and High-Stability Continuous Generation System for NitrousAcid. Environmental Science \& Technology, 1995. 29(9): p. 2390-2395.

24. Bongartz, A., et al, Near-Uv Absorption Cross-Sections and Trans Cis Equilibrium of Nitrous-Acid. Journal of Physical Chemistry, 1991. 95(3): p. 1076-1082.

25. Jones, L.H., R.M. Badger, and G.E. Moore, The Infrared Spectrum and the Structure of Gaseous Nitrous Acid. Journal of Chemical Physics, 1951. 19(12): p. 1599-1604.

26. Mcgraw, G.E., D.L. Bernitt, and Hisatsun.Ic, Infrared Spectra of Isotopic Nitrous Acids. Journal of Chemical Physics, 1966. 45(5): p. 1392-\&.

27. Sironneau, V., et al, Absolute line intensities of HONO and DONO in the far-infrared and redetermination of the energy difference between the trans- and cis-species of nitrous acid. Journal of Molecular Spectroscopy, 2010. 259(2): p. 100-104.

28. Varma, R. and R.F. Curl, Study of N2o3-H2o-Hno2 Equilibrium by Intensity Measurements in Microwave Spectroscopy. Journal of Physical Chemistry, 1976. 80(4): p. 402-409.

29. Becker, K.H., et al., Solubility of nitrous acid (HONO) in sulfuric acid solutions. Journal of Physical Chemistry, 1996. 100(36): p. 14984-14990.

30. Chameides, W.L., The Photochemistry of a Remote Marine Stratiform Cloud. Journal of Geophysical Research-Atmospheres, 1984. 89(Nd3): p. 4739-4755.

31. Goretski, J., O.C. Zafiriou, and T.C. Hollocher, Steady-State Nitric-Oxide Concentrations during Denitrification. Journal of Biological Chemistry, 1990. 265(20): p. 11535-11538.

32. Lelieveld, J. and P.J. Crutzen, The Role of Clouds in Tropospheric Photochemistry. Journal of Atmospheric Chemistry, 1991. 12(3): p. 229-267.

33. Zhou, X.L., et al., Photochemical production of nitrous acid on glass sample manifold surface. Geophysical Research Letters, 2002. 29(14): p. -.

34. Loo, B.W. and C.P. Cork, Development of High-Efficiency Virtual Impactors. Aerosol Science and Technology, 1988. 9(3): p. 167-176.

35. Marple, V.A. and C.M. Chien, Virtual Impactors - a Theoretical-Study. Environmental Science \& Technology, 1980. 14(8): p. 976-985. 
36. Ellis, R.A., et al, Characterizing a Quantum Cascade Tunable Infrared Laser Differential Absorption Spectrometer (QC-TILDAS) for measurements of atmospheric ammonia. Atmospheric Measurement Techniques, 2010. 3: p. 397-406.

37. Herndon, S.C., et al, Airborne measurements of $\mathrm{HCHO}$ and $\mathrm{HCOOH}$ during the New England Air Quality Study 2004 using a pulsed quantum cascade laser spectrometer. Journal of Geophysical ResearchAtmospheres, 2007. 112(D10): p. - .

38. McManus, J.B., et al, Application of quantum cascade lasers to high precision atmospheric trace gas measurements. Optical Engineering, 2010. 49(11). 